\title{
Sugar levels relate to aggression in couples without supporting the glucose model of self-control
}

\author{
Florian Lange $^{1 *}$ and Robert Kurzban ${ }^{2}$ \\ ${ }^{1}$ Department of Neurology, Hannover Medical School, Hannover, Germany \\ 2 Department of Psychology, University of Pennsylvania, Philadelphia, PA, USA \\ *Correspondence: lange.florian@mh-hannover.de
}

Edited by:

John M. Zelenski, Carleton University, Canada

Reviewed by:

Martin S. Hagger, Curtin University, Australia

Evan C. Carter, University of Minnesota, USA

Keywords: blood glucose, self-control, aggression, self-regulation, ego depletion

\section{A commentary on}

Low glucose relates to greater aggression in married couples

by Bushman, B. J., DeWall, C. N., Pond, R. S., and Hanus, M. D. (2014). Proc. Natl. Acad. Sci. U.S.A. 5:572. doi: 10.1073/pnas.1400619111

As researchers in the field of selfcontrol, we read the recent publication by Bushman et al. (2014) with great interest. Using creative measures of aggressive tendencies, the authors examined the relationship between blood glucose levels and proxies for intimate partner violence. Across 3 weeks of testing, daily measures of blood glucose appeared to be related to the number of needles participants stuck in a voodoo doll supposed to represent their partner. On a subsequent laboratory task, participants with low average glucose levels exposed their spouses to more aversive noise.

From their results, Bushman et al. (2014) concluded that glucose "influences aggressive tendencies and behaviors" (p. 3) within couples. They regarded their findings as implying that "interventions designed to provide individuals with metabolic energy might foster more harmonious couple interactions" (p. 3). While there is obvious appeal to the notion that glucose can increase self-control and thus prevent aggressive impulses from being expressed, this study does not provide evidence supporting this idea.

The work by Bushman et al. draws on the proposal that "self-control requires brain food in the form of glucose" (p. 3).
However, the glucose model of self-control (Gailliot et al., 2007) suffers from both conceptual shortcomings and empirical falsification (Kurzban et al., 2013). Not only has the proposal that glucose fuels the part of the brain needed to exert selfcontrol been shown to be inconsistent with what is known about brain metabolism (Kurzban, 2010), but the empirical evidence reported in support of the proposal has been demonstrated to be implausible from a statistical perspective (Schimmack, 2012). Note that the original multi-study report by Gailliot et al. (2007) argued that self-control depletion is mediated by blood glucose levels on the basis of nine studies, all of which produced significant results. Across these studies, effect sizes were strongly negatively correlated with sample sizes, and the probability of obtaining the observed pattern of only significant results was less than $1 \%$, (Schimmack, 2012), implying that the role of blood glucose in determining self-control capacities is likely to be overstated. This conclusion is further corroborated by replication studies that did not find the originally reported effect (Lange and Eggert, 2014; Lange et al., in press) as well as additional work suggesting that rinsing one's mouth with glucose is sufficient to counteract self-control fatigue (Molden et al., 2012; Sanders et al., 2012; Hagger and Chatzisarantis, 2013; see also Carter and McCullough, 2013).

In view of these issues, self-control and blood glucose levels cannot simply be equated. As a consequence, when relating their outcome measure to blood sugar concentrations, Bushman et al. (2014) did not test, as they claim, "the effects of self-control on aggression" (p. 3). What they did test was the size of the relationship between daily fluctuations in blood glucose levels and a measure of aggressive impulse. Importantly, the authors did not record any self-control data and assuming that the number of pins stuck in a doll varies according to individuals' ability to exert self-control is conceptually problematic. For the daily assessment of aggressive tendencies, participants were simply asked to indicate how angry they were with their partner. They were not required to inhibit or override their aggressive thoughts, emotions, or urges. Hence, the only conclusion licensed by the findings reported by Bushman et al. is that blood glucose relates to a single-item self-report measure of aggressive impulse, not to the ability to control these impulses. We do not doubt that hungrier organisms are more aggressive. This accords with our everyday experience, the animal literature (e.g., Cook et al., 2000), and the Snickers ad campaign, "You're Not You When You're Hungry." However, this observation does not imply that glucose reflects the fuel necessary to muster the willpower not to harm one's partner.

For their second analysis, mean blood glucose levels across 3 weeks were related to aggressive behavior toward the partner. Analyzed in this way, glucose levels do not indicate the current state of a fluctuating self-control resource, but are rather a trait variable. This has important implications for the authors' conclusions. The more aggressive participants on the laboratory 
task were not those who were ego-depleted or hungry in that particular moment. They had low blood sugar concentration in general, a trait that can be linked to aggression via numerous third variables. With increasing age, for instance, mean blood glucose levels increase (Dahle et al., 2009), while aggression diminishes (McLaughlin et al., 1992; Barbaree et al., 2003). Whereas the reported correlation might provide information about the biology of individual differences in aggression, it does not support the glucose model of self-control.

Experimental studies manipulating participants' blood sugar concentration might provide evidence for the claim that "glucose levels are an important influence on self-control and aggression" (p. 3). To date, however, experimental evidence is insufficient to support a significant role of glucose in self-control fatigue (Kurzban et al., 2013). Likewise, Bushman et al.'s study does not demonstrate that fluctuations in blood glucose affect individuals' self-control abilities. As an important consequence, there is no reason to assume that giving couples a sugary "boost to their self-control energy" (p. 3) will reduce intimate partner violence. Because the glucose model of self-control lacks empirical foundation, it does not qualify as a framework for scientifically based intervention strategies.

\section{REFERENCES}

Barbaree, H. E., Blanchard, R., and Langton, C. M. (2003). The development of sexual aggression through the life span. Ann. N. Y. Acad. Sci. 989, 59-71. doi: 10.1111/j.1749-6632.2003.tb07293.x
Bushman, B. J., DeWall, C. N., Pond, R. S., and Hanus, M. D. (2014). Low glucose relates to greater aggression in married couples. Proc. Natl. Acad. Sci. U.S.A. 5:572. doi: 10.1073/pnas. 1400619111

Carter, E. C., and McCullough, M. E. (2013). After a pair of self-control-intensive tasks, sucrose swishing improves subsequent working memory performance. BMC Psychol. 1:22. doi: 10.1186/20507283-1-22

Cook, M. I., Monaghan, P., and Burns, M. D. (2000). Effects of short-term hunger and competitive asymmetry on facultative aggression in nestling black guillemots Cepphus grylle. Behav. Ecol. 11, 282-287. doi: 10.1093/beheco/ 11.3.282

Dahle, C. L., Jacobs, B. S., and Raz, N. (2009). Aging, vascular risk, and cognition: blood glucose, pulse pressure, and cognitive performance in healthy adults. Psychol. Aging 24, 154-162. doi: 10.1037/a0014283

Gailliot, M. T., Baumeister, R. F., DeWall, C. N., Maner, J. K., Plant, E. A., Tice, D. M., et al. (2007). Self-control relies on glucose as a limited energy source: willpower is more than a metaphor. J. Pers. Soc. Psychol. 92, 325-336. doi: 10.1037/0022-3514.92.2.325

Hagger, M. S., and Chatzisarantis, N. L. (2013). The sweet taste of success: the presence of glucose in the oral cavity moderates the depletion of selfcontrol resources. Pers. Soc. Psychol. B. 39, 28-42. doi: $10.1177 / 0146167212459912$

Kurzban, R. (2010). Does the brain consume additional glucose during self-control tasks? Evol. Psychol. 8, 244-259. Available online at: http://www.epjournal.net/wp-content/uploads/ep 08244259.pdf

Kurzban, R., Duckworth, A., Kable, J., and Myers, J. (2013). An opportunity cost model of subjective effort and task performance. Behav. Brain Sci. 36, 661-679. doi: 10.1017/S0140525X12003196

Lange, F., and Eggert, F. (2014). Sweet delusion. Glucose drinks fail to counteract ego depletion. Appetite 75, 54-63. doi: 10.1016/j. appet.2013.12.020

Lange, F., Seer, C., Rapior, M., Rose, J., and Eggert, F. (in press). Turn in all you want: still no effect of sugar consumption on ego depletion. J. Eur. Psychol. Stud.

McLaughlin, I. G., Leonard, K. E., and Senchak, M. (1992). Prevalence and distribution of premarital aggression among couples applying for a marriage license. J. Fam. Viol. 7, 309-319. doi: 10.1007/ BF00994621

Molden, D. C., Hui, C. M., Noreen, E. E., Meier, B. P., Scholer, A. A., D’Agostino, P. R., et al. (2012). The motivational versus metabolic effects of carbohydrates on self-control. Psychol. Sci. 23, 1130-1137. doi: 10.1177/0956797612 439069

Sanders, M. A., Shirk, S. D., Burgin, C. J., and Martin, L. L. (2012). The gargle effect: rinsing the mouth with glucose enhances self-control. Psychol. Sci. 23, 1470-1472. doi: 10.1177/0956797612450034

Schimmack, U. (2012). The ironic effect of significant results on the credibility of multiple-study articles. Psychol. Methods 17, 551-566. doi: 10.1037/a0029487

Conflict of Interest Statement: The authors declare that the research was conducted in the absence of any commercial or financial relationships that could be construed as a potential conflict of interest.

Received: 11 May 2014; paper pending published: 21 May 2014; accepted: 22 May 2014; published online: 10 June 2014.

Citation: Lange F and Kurzban R (2014) Sugar levels relate to aggression in couples without supporting the glucose model of self-control. Front. Psychol. 5:572. doi: 10.3389/fpsyg.2014.00572

This article was submitted to Personality and Social Psychology, a section of the journal Frontiers in Psychology.

Copyright (c) 2014 Lange and Kurzban. This is an open-access article distributed under the terms of the Creative Commons Attribution License (CC BY). The use, distribution or reproduction in other forums is permitted, provided the original author(s) or licensor are credited and that the original publication in this journal is cited, in accordance with accepted academic practice. No use, distribution or reproduction is permitted which does not comply with these terms. 